\title{
ON MIXED HÖLDER-MINKOWSKI INEQUALITIES AND TOTAL CONVEXITY OF CERTAIN FUNCTIONS IN $\mathscr{L}^{p}(\Omega)$
}

\author{
C. A. ISNARD AND A. N. IUSEM*
}

Abstract. We prove the following mixed Hölder-Minkowski-type inequalities for all $x, z \in$ $\mathscr{L}^{p}(\Omega)$ :

$$
\begin{gathered}
0 \leqslant \frac{\|z\|_{p}^{p-s}}{s}\left[\left(\|x\|_{p}+\|z\|_{p}\right)^{s}-\|x+z\|_{p}^{s}\right] \leqslant\|x\|_{p}\|y\|_{q}-\operatorname{Re}(\langle x, y\rangle) \quad \text { if } 1 \leqslant s \leqslant p \leqslant 2, \\
\frac{\|z\|_{p}^{p-s}}{s}\left[\left(\|x\|_{p}+\|z\|_{p}\right)^{s}-\|x+z\|_{p}^{s}\right] \geqslant\|x\|_{p}\|y\|_{q}-\operatorname{Re}(\langle x, y\rangle) \geqslant 0 \text { if } 2 \leqslant p \leqslant s,
\end{gathered}
$$

where $y \in \mathscr{L}^{q}(\Omega)$ is defined as $y(\xi)=|z(\xi)|^{p-2} z(\xi)$, if $z(\xi) \neq 0, y(\xi)=0$ otherwise, and $1 / p+1 / q=1$. Next we consider the Bregman distance $D_{f}: \mathscr{L}^{p}(\Omega) \times \mathscr{L}^{p}(\Omega) \rightarrow \mathbf{R}$ defined as $D_{f}(x, y)=f(x)-f(y)-\left\langle f^{\prime}(y), x-y\right\rangle$, with $f(x)=\|x\|_{p}^{S}(s, p>1)$, and prove that $\inf \left\{D_{f}(u, z):\|u-z\|_{p}=t\right\}>0, \sup \left\{D_{f}(u, z):\|u-z\|_{p}=t\right\}<\infty$, for all $p, s>1$, all $z \in \mathscr{L}^{p}(\Omega)$ and all $t>0$, so that the Bregman distance induced by $f(x)=\|x\|_{p}^{S}$ and the metric distance $d(x, y)=\|x-y\|_{p}$ are topologically equivalent. As a consequence, this $f$ can be used in projection algorithms for the convex feasibility problem and generalized proximal point methods for convex optimization in $\mathscr{L}^{p}(\Omega)$.

Mathematics subject classification (1991): 46B10, 46B25, 46E30.

Key words and phrases: Banach spaces, Hölder's inequality, Minkowski's inequality.

\section{REFERENCES}

[1] AlBeR, YA. I., Metric and generalized projection operators in Banach spaces: properties and applications, In Theory and Applications of Nonlinear Operators of Monotone and Accretive Type (A. Kartsatos, editor), Marcel Dekker, New York (1996), 15-50.

[2] Alber, Ya. I, BurachiK, R. S., IUSEM, A. N., A proximal point method for nonsmooth convex optimization problems in Banach spaces, Abstract and Applied Analysis 2 (1997), 97-120.

[3] ARAUJO, A., The non-existence of smooth demands in general Banach spaces, Journal of Mathematical Economics 17 (1988), 309-319.

[4] BREGMAN, L. M., The relaxation method of finding the common points of convex sets and its application to the solution of problems in convex programming, USSR Computational Mathematics and Mathematical Physics 7 (1967), 200-217.

[5] BURACHIK. R. S., IUSEM, A. N., A generalized proximal point algorithm for the variational inequality problem in a Hilbert space, (to be published in SIAM Journal on Optimization).

[6] BUtNARIU, D., IUSEM, A. N., Local moduli of convexity and their application to finding almost common points of measurable families of operators, AMS Contemporary Mathematics 204 (1997), 61-91.

[7] BUtnaRIU, D., IUSEM, A. N., On a proximal point method for convex optimization in Banach spaces, Numerical Functional Analysis and Optimization 18 (1997), 723-744.

[8] BUTNARIU, D., IUSEM A. N., BURACHIK, R. S., Iterative methods of solving stochastic convex feasibility problems and applications, Computational Optimization and Applications 15 (2000), 269-307. 
[9] Censor, Y., De Pierro, A. N., Elfving, T., Herman, G. T., Iusem, A. N., On iterative methods for linearly constrained entropy maximization, In Numerical Analysis and Mathematical Modelling (A. Waculicz, editor). Banach Center Publication Series, Banach Center, Warsaw 24 (1990), 145-163.

[10] CENSOR, Y., ZENIOS, S., The proximal minimization algorithm with D-functions, Journal of Optimization Theory and Applications 73 (1992), 451-464.

[11] CHEN, G., TeBoulle, M., Convergence analysis of proximal-like optimization algorithm using Bregman functions, SIAM Journal on Optimization 3 (1993), 538-543.

[12] Clarke, F. H., Optimization and Nonsmooth Analysis. John Wiley, New York (1983).

[13] DE PIERRO, A. R., IUSEM, A. N., A relaxed version of Bregman's method for convex programming, Journal of Optimization Theory and Applications 51 (1986), 421-440.

[14] ECKSTEIN, J., Nonlinear proximal point algorithms using Bregman functions, with applications to convex programming, Mathematics of Operations Research, 18 (1993), 202-226.

[15] IUSEM, A. N., On some properties of generalized proximal point methods for quadratic and linear programming, Journal of Optimization Theory and Applications 85 (1995), 593-612.

[16] IusEM, A. N., ISNARD, C. A., ButNARIU, D., A mixed Hölder and Minkowski inequality, Proceedings of the American Mathematical Society 127 (1999), 2405-2415.

[17] KIWIEL, K. C., Proximal minimization methods with generalized Bregman functions, SIAM Journal on Control and Optimization 35 (1997) 1142-1168.

[18] KIWIEL, K. C., Free-steering relaxations methods for problems with strictly convex costs and linear constraints, Mathematics of Operations Research 22 (1997) 326-349.

[19] Mitrinović, D. S., PeČArić, J. E., FinK, A. M., Classical and New Inequalities in Analysis, Kluwer, Dordrecht (1993).

[20] Vladimirov, A. A., Nesterov, Y. E., Chekanov, Y. N., Uniformly convex functionals, Vestnik Moskovskogo Universiteta, Series Mathematika i Kybernetika 3 (1978) 12-23. 